\title{
Persona en Apocalipsis apócrifo de Armando Uribe Arce
}

\section{Person in Apocalipsis apócrifo by Armando Uribe Arce}

\section{Pedro Aldunate Flores}

Universidad de Concepción. Concepción, Chile

pedroaldunate@gmail.com

\section{RESUMEN}

Este artículo propone una síntesis de la problemática del paso por la muerte -aporía en Derrida- en el contexto de la ficción poética presentada en el libro Apocalipsis apócrifo por el poeta, histrión literario, Armando Uribe Arce. La lectura se organiza a partir de la visualización del texto como escena de metalepsis de autor. Se define y caracteriza la condición de los sujetos, en el contexto de la creación de un más allá infierno, purgatorio, cielo- que otorgaría la base a la pregunta filosófico-antropológica por la persona en su trance y estado de muerte.

Palabras claves: Persona, muerte, escena, aporía, metalepsis, espectro.

\section{ABSTRACT}

This article proposes a synthesis of problematic of the passage by the death -aporía in Derrida- in the context of the poetic fiction presented in the book Apocalipsis apócrifo by the poet, literary histrión, Armando Uribe Arce. The reading is organized from

* Este artículo ha sido extraído de la tesis doctoral "Diario de muerte de Enrique Lihn y Apocalipsis apócrifo de Armando Uribe: Escenas del Histrión y la Muerte” dirigida por Gilberto Triviños, año 2009, Universidad de Concepción, Chile. Muy especialmente, en memoria de Gilberto Triviños, maestro de estos tránsitos y de otros (Q.E.P.D). Me detengo en el concepto de persona evidenciando también aquí la huella de Ingmar Bergman, director sueco fallecido en 2007. 
the visualization of the text like scene of metalepsis of author. The condition of the subjects is defined and characterized, in the context of the creation of beyond -a hell, purgatory, sky- that would grant the base to the question by the person in its critical moment and state of death.

Keywords: Person, death, scene, aporía, metalepsis, spectre.

Recibido: 03/01/2010. Aceptado: 20/05/2010.

La sentencia interlocutoria suspendiendo por ahora el proceso pendiente, el juicio personal, me impuso la labor transitoria (es un servicio público) de recorrer estos lugares negativos del Otro mundo, para instruirme e informar por escrito, como lo he estado haciendo, a los demás interesados, sobre qué ocurre a mi juicio en purgatorio e infierno y en los caminos oscurecidos subterráneos que a ellos llevan indefectiblemente.

Quise confortarme pensando que si redactaba bien el Informe, ello sería un Bien a mi favor y que esto conduciría a aquel tribunal especial personal, tal vez, a señalarme la vía exclusiva al purgatorio.

Pero me dije a la vez que quizás dicha sentencia implica que mi destino es el Infierno, y el recorrido que hice y aún hago es ya un castigo de condena, pues incluso mi Informe está mal escrito y es inmoral, ya que se refiere al Mal.

(Armando Uribe Arce, 2006b)

M

e propongo sintetizar, en este artículo, algunas observaciones preliminares en torno a la condición de algunos sujetos textuales presentes en el texto poético Apocalipsis apócrifo publicado en 2006 por el poeta Armando Uribe Arce, Premio Nacional de Literatura, año 2004. Desde mi perspectiva, visualizo de forma general el texto como escena de metalepsis y, paralelamente, discuto la noción de muerte propuesta por Jacques Derrida en sus Aporias (1998).

De manera específica, establezco relaciones entre el concepto de la figura de la "metalepsis del autor", acotada por Gérard Genette en Metalepsis. 
De la figura a la ficción (2004) y ciertas reflexiones que se desprenden del pensamiento de Jacques Derrida en torno a la noción de espectro, nombre propio y, muy especialmente, en torno al concepto y experiencia de muerte, entendida como "lugar de la aporía" o como el lugar donde la muerte como problema deja de ser tal, como lo señala el mismo Derrida: "Allí, en resumidas cuentas, en ese lugar de aporía, ya no hay problema” (1998: 30). Sin embargo, se trata de un desplazamiento de los sujetos hacia ese (no) lugar, en suma, y al decir de Derrida: "de lo que va es de un cierto paso"1.

¿En qué consiste la figura retórica de la "metalepsis de autor”? y ¿cuál sería el sentido de identificar dicha figura en el marco del comentario de textos líricos? Estamos en presencia de la "metalepsis de autor" cuando, específicamente -y siguiendo la definición clásica de Fontanier- se procede a "transformar a los poetas en (los) héroes de las hazañas que celebran (o en) representarlas como si ellos mismos causaran los efectos que pintan o cantan" (Genette, 2004: 10). Así, según Genette, "vemos que la metalepsis de autor puede conjugarse tanto en primera como en tercera persona (...) En ambas, (el poeta) pretende intervenir en la historia que sólo representa" (2004: 14).

En suma, de lo que va o de lo que trata, siguiendo la formula de Derrida, es de un cierto paso o traslado de lo real a lo ficticio, del contexto de la enunciación hacia la enunciación en sí o del mundo referencial al mundo representado, pero por un paso explícitamente establecido, con fines tanto estéticos como éticos. Cabe aclarar que tanto en el caso de metalepsis como en el de la aporía, de lo que va o de lo que se habla es de un cierto paso o traslación -propio de las figuras como la metáfora, la metonimia y la metalepsis-. Sin duda, la literatura está llena de pasos, fugas, traslados, devenires según Deleuze o desplazamientos, ya sea de los mismos sujetos dentro de la ficción creada o, como sucede aquí, del autor en su condición metaléptica, es decir, de sujeto autorial transformado en héroe. ¿Pero hacia dónde conduce esta mirada del autor introducida en su obra mediante el procedimiento figurativo de la metalepsis?, ¿y para qué, en última instancia, se crea este juego entre el autor y la obra?, ¿con qué fin?, en el supuesto de que todo paso tenga su fin.

En el texto Apocalipsis apócrifo se enuncian algunas respuestas a estos

${ }^{1}$ La oración en francés es: il y va d'un certain pas. El propio traductor de Derrida reconoce la falta de potencia de la expresión traducida a otra lengua distinta del francés, ya que la palabra pas significa tanto la idea de paso o de la cuestión (en español) como, a su vez, la idea de negación. Se trata de una expresión aporética, en suma, pues de lo que va es de un cierto paso y de la negación del mismo, es decir, de la detención de ese paso en un lugar determinado como lo es la muerte (Derrida, 1998: 22). 
cuestionamientos que, como lo revelan los personajes de la ficción creada, están lejos de promover una cierta comodidad de los sujetos respecto de sus desplazamientos en el ámbito de la versión del fin del mundo o Apocalipsis apócrifo que el poeta se representa para sí. Una primera lectura ya nos revela que de lo que va es de un cierto paso, al decir recurrentemente con Derrida, pero también de un paso intergenérico que hibridiza de manera evidente la noción de poema o más estrictamente de género lírico ${ }^{2}$, haciendo estallar toda teoría general o natural de los géneros literarios, especialmente en lo que respecta a sus rasgos formales, de modo que estamos en presencia de un devenir transgenérico del texto poético, lo cual es apuntado por Armando Roa en el prólogo a La fe el amor la estupidez del año 2006. Cito:

Su obra, que rebasa el estrecho molde de los géneros, se resiste a clasificaciones y escuelas.

(...)

A veces en un mismo poema el Uribe sentencioso y admonitorio juega con el Uribe mordaz y coloquial, o bien con el Uribe más elegíaco y sombrío. Creo que pocos poetas chilenos contemporáneos han logrado amalgamar de manera más versátil las rupturas de la continuidad y la continuidad de las rupturas, el poema y el antipoema, estableciendo un puente revitalizador de la tradición (Uribe, 2006a: 17-18).

Y este "rebase" de la teoría de los géneros es visible, de manera evidente, en el libro que aquí recorro -puesto que el mismo libro es un viaje-, y el cual se presenta como poema, ensayo, diario de viaje, Informe y, muy especialmente, como juicio personal, además de versión (apócrifa) del infierno (y del cielo) cristiano-católico.

Cuando abrimos este texto, prolífico en cadáveres y condenados -espectros del escritor-, nos damos cuenta, en primer lugar, que no estamos hablando de un texto lírico propiamente tal -al menos no en el sentido tradicional- sino también de un diario de vida, o también un ensayo sobre el lugar de una utopía o mejor dicho de una distopía a propósito del fin de nuestros días -o del fin de los días del autor-; pero también de un Informe

2 Señala José Guilherme Merquior: "La lírica era en un principio, como se sabe, apenas un género poético entre otros; sin embargo, con la perdida de vigencia del gran poema narrativo y del verso dramático, las nociones de lírica y poesía acabaron por confundirse. En un examen de la literatura moderna, ambos términos resultan intercambiables. La principal consecuencia de esta identificación estriba en que la lírica devino la depositaria por excelencia de una característica esencial de la poesía la de función lingüística específica” (Merquior, 1999: 85). 
("mal escrito") que se refiere a la historia del pueblo de Chile, transfigurado en la mítica ciudad de Dite, cuidad al revés situada al centro del dantesco purgatorio donde se llama -o donde el poeta llama- a pagar todas las crueldades de la historia humana; pero también y como lo revela el título estamos ante una versión -reescritura- de un texto religioso, es decir, de un cierto paso desde el texto bíblico canónico al texto apócrifo, paso virtuoso, en este caso, que conecta esta literatura con la narrativa de Borges.

¿Cómo sucede este paso? Sucede, en primer lugar, en el cruce que se da al comienzo del texto, entre el género del ensayo autobiográfico y el poema propiamente tal. Para ello el propio sujeto textual problematiza sobre la cuestión no menor de la condición del hablante o yo lírico del poema. Esta reflexión metalingüística es, para el desarrollo del texto, primordial, de suerte que se convierte en un primer estado o condición del paso o del propio paseo del sujeto por el infierno escatológico representado en el poema. Las relaciones entre Apocalipsis apócrifo y Una temporada en el infierno de Rimbaud (1994) son sugerentes desde los primeros pasos del poema del autor chileno, texto que también transita entre el ámbito de la narrativa del viaje y de la lírica propiamente tal. Es el propio Uribe, en apariencia, quien habla en nombre de sí mismo, discutiendo el acertado descubrimiento de Rimbaud según el cual todo sujeto textual es otro. "El yo es otro" nos dice Rimbaud, pero resulta que este otro yo del poeta Uribe habla del propio Uribe, de su propia vida y de su propia condición como autor del texto que escribe y del tremebundo infierno que nos representa y que, sin duda, el mismo autor espera ansiosamente visitar.

La condición del sujeto como apariencia -o en el caso de Enrique Lihn, máscara o personaje- me permite profundizar, en este aspecto, y desde el pensamiento de Derrida, en la noción de la figura metaléptica -autor devenido héroe de su relato- como figura espectral, huella ahora intangible pero aún visible del escritor devenido héroe, que precisamente en su devenir metaléptico aparece en tanto espectro, tal como lo plantea Jacques Derri$\mathrm{da}^{3}$. Se trata efectivamente de un espectro, el sujeto que deambula por ese

${ }^{3}$ La figura del espectro es presentada por Jacques Derrida en su libro Espectros de Marx. Luego, en su Exordio a los Espectros de Marx el filósofo sugiere la ética y la didáctica de los espectros (espíritus y/o fantasmas): "Lo que ocurre entre ambas (vida y muerte) y entre las dos o como se quiera, como entre vida y muerte, eso sólo puede mantenerse de algún fantasma. Sería necesario entonces aprender de los espíritus. Incluso y sobre todo si eso, lo espectral, no está. Incluso sobre todo si eso, ni sustancia ni esencia ni existencia, no está nunca presente como tal. El tiempo del aprender a vivir' un tiempo sin presente tutor, volvería a esto, a exordiar (lo) que nos provoca: aprender a vivir con los fantasmas, en la conversación, la compañía o el compañerismo, en el comercio sin comercio de fantasmas. A vivir de otra manera y mejor, No mejor, sino justamente. Pero con ellos. Y este ser 
lugar -infierno- y no lugar -muerte- a la vez que ese espacio es proyectado, imaginado y situado en el más allá que él mismo héroe recorre e inventa con su palabra. Palabra de espectro, cadáver parlante, mortuus transfigurado en el pasajero de una utopía -sueño-; destinador y destinatario de un objeto cada vez más incomprendido: la verdad del bien y del mal, en sentido físico y metafísico, en sentido histórico y metahistórico; en suma, héroe espectral transmutado en voz y visión, utopía de la poesía del versificador Uribe Arce que no sólo está llamado a pasar por ese (no) lugar-muerte- sino que, a partir de la condición de pasada, está sujeto a re-transmitir su imagen -espectro de luz- como última habitación o como último residuo -huella- de ese autor metaléptico devenido héroe del relato. Espectro en tanto la voz que habla -dispositivo colectivo de enunciación- es también ahora la voz y la visión condenada a su propio castigo, a su constante deambular por los espacios imaginados del apocalipsis que nos hemos inventado, no en el más allá de los "relatos apaciguadores" o "esperanzadas fantasmagorías", sino en el concreto espacio de la historia. Así el histrión, mediante metalepsis, se espectra y acaso con ello espectra los fantasmas y horrores de la historia. Invención, visualización del espectro como condena de los pecados mortales y humanos, que muestra y a la vez habita en el ámbito de su nocturno paseo, en su viaje hacia luz-divinidad. Uribe entonces es ahora el espectro condenado a la imagen de su figura creada y no sólo eso -ya que en ese paso el poeta será héroe de su ficción-, sino que en su voz se sintetizan todas las voces de los condenados de la historia, todos los lamentos de los que no son ni serán llamados a habitar en la luz. Espectros de Uribe en definitiva, aquel sujeto que perdura en el tránsito o en el paso por los abismos sin luz del más allá. En ese espectro yacen, adosados a su propia imagen, todos los condenados de la historia (Hitler y Pinochet, por ejemplo) y de este modo la ficción literaria no es sino el espejo invertido (infierno, apocalipsis apócrifo) de la realidad histórica que el autor observa y luego ficcionaliza, lográndose de esta manera el proyecto ético, didáctico y crítico de la obra en cuestión. La crítica deconstruye las metáforas de la historia y esa crítica se vuelve una autocrítica del sujeto histórico que es el autor, espectrado en su poesía. Escribiendo el autor aprende a vivir y morir, no sabe vivir, aprende a vivir, en este caso, reescribiendo la historia desde su memoria. Dice Derrida: "Vivir, por definición, eso no se aprende. No de sí mismo, sino de la vida a través de

con espectros también sería una política de la memoria, de la herencia y las generaciones" (Derrida, 1997: 8). Enseñanza del héroe metaléptico y espectral, Armando Uribe Arce, sujeto que está y no está presente tanto en vida como en ficción poética, espectro que habla para devolver a la luz la historia o el infierno de nuestras vidas, atadas a sus existencias. 
la vida. Solamente del otro y de la muerte. En todo caso, del otro al borde de la vida. En el borde interno o en el borde externo", escribir "es una heterodidáctica entre la vida y la muerte" (Derrida, 1997: 8). Fin último de la metalepsis: espectrarse en el abismo de lo propio para asir la luz en el agujero (in)franqueable de las tinieblas. Espectrarse más allá de la vida, en la muerte, para poder morir en paz, para poder vivir en paz, es lo mismo. Fin último de la literatura según Deleuze: "escribir por ese pueblo que falta", ese pueblo que sin duda se encuentra más allá del borde de nuestra vida y muerte, o en el entre en que habitan los espectros. Crítica no del más allá, sino del más acá que nos conduce primero a ese paso hacia el espectro, presencia que a su vez "ata las miradas del pavor, como el equilibrista ante el alambre", y que luego las devuelve al lector, horrorizándonos ante la verdad del crimen, la injusticia, la blasfemia, la ira, la violencia, el orgullo, la soledad del pecador que lo condena más acá -y por especulación del artificio poético-, más allá del límite que define nuestro destino: la muerte, lugar del paso (im)posible hacia ese otro (no lugar), el infierno.

Sin embargo, el espectro también es héroe, en tanto que figura metaléptica del relato. Este es el primer paso de este viaje hacia los infiernos del versificador, metalepsis de la persona que escribe, luego la aporía -descubrimiento de la muerte como lugar y no lugar- y en ese lugar, voz y visión devenida espectro. Dice el sujeto:

Fui concebido la misma noche en que Adolfo Hitler celebraba su triunfo asomándose a una ventana de la cancillería de Berlín, en el momento mismo en que saludaba, y nací nueve meses después a fines de octubre de 1933.

Hitler presidió mi nacimiento distante, al Sur de América de Sur, en la calle Cumming esquina de Santo Domingo.

No se trata de mi vida sino de cuanto ocurrió por años de años mientras aún vivía.

Años del anticristo en todas partes, y yo testigo suyo en muchas.

Decir "yo" es un decir.

Testimoniar de su carne, cuerpo y psique, de sus hechos, actos y omisiones crudelísimos, no es decir solamente; es verbo de una frase gramatical interminable e inconmensurable que gracias a Dios, Laus Deo, no es infinita ni eterna (Uribe, 2006b: 15).

El procedimiento metaléptico aquí apuntado le permite al sujeto textual un giro hacia la propia-vida, hacia el relato específico del nacimiento mis- 
mo del autor, en las circunstancias históricas "reales"; pero más allá de eso la metalepsis permite introducir la historia misma dentro del ámbito de la representación creada, aun cuando el sujeto niegue tal propósito al señalar que "no se trata de mi vida sino de cuanto ocurrió por años de años mientras vivía" (2006b: 16). Esa vida contada en años y años se traslada al texto literario, justamente como una memoria de intensidades y tal como en La divina comedia, el tránsito imaginado por el sujeto permite el encuentro tanto con personas vivas o muertas, conocidas por el autor del libro, y condenadas en su propio libro testamentario. La entrada al infierno revela el tono de las visiones del histrión, en donde nuevamente se nos habla del espacio mortal e infernal como hoyo donde, sucesivamente:

Iremos penetrando en camino hacia las antesalas del juicio final, el del término de todo lo creado, el universo, la tierra esférica entre los polos planos, acinturada por el ecuador; fin de la vida animal, vegetal, y de inmovilidad de los minerales, y de los seres criaturas humanas entre los cuales me cuento. No se trata de mí sino de la cuasi totalidad (2006b: 17).

La metalepsis es, entonces, un procedimiento crítico que se logra con la inclusión explícita de la figura del autor en su obra, con lo cual la misma historia humana se reescribe en el espacio de la ficción.

El poeta devenido héroe de la hazaña del paso por y más allá del infierno introduce el giro total de contar la historia planetaria desde la propia ficción, es decir, desde la fabulación de ese Apocalipsis apócrifo que el mismo poeta (se) inventa. Con ello acaso el poeta se revela, precisamente, ante el imperativo según el cual no es posible "manejar el pasado $-y$ acaso tampoco el porvenir" (Genette, 2006: 14). Con ello el paso conduce no sólo a un sujeto hacia ese otro mundo infernal y apocalíptico que se revelará más adelante, a medio camino entre la muerte y el fin de la misma en el espacio del purgatorio y el infierno, sino que ese paso permite el desplazamiento de un pueblo hacia otro lugar, por lo cual estamos, sin duda, en presencia de un dispositivo colectivo de la enunciación al decir de Deleuze y Guattari (1990). Con el yo del poema pasamos nosotros a constituir ese cuerpo histórico que se descompone literalmente en la ficción del poeta Uribe Arce. Pasamos afuera de este mundo hacia el infierno con el poeta Uribe como héroe apocalípticodantesco y como figura autorial que cuenta sus pecados, entre ellos el pecado literario de la difamación que lo sorprende en un rincón estrecho del mismo pasadizo: 
Difamar es tarea de palabreros y escritores, y éstos se deleitan esparciendo rumores infamantes, injurias, calumnias, denuestos, revelando secretos vergonzosos sobre el cuerpo y la psique de muchos con nombre y apellidos, misterios verdaderos o falsos, por igual.

Me encuentro con una casilla destinada a mí por difamador, en conversaciones, en libros impresos y en este mismo Apocalipsis apócrifo (2006b: 51).

Así el sujeto, siendo juez y condenado al mismo tiempo, descubre en el infierno su propio libro testamentario que lo condena, más allá de la vida terrestre, justamente en el paso por las amplias esferas del infierno y el purgatorio; pero a la vez ese lúgubre paseo por la memoria de la culpa lo salva, al menos literariamente hablando, siendo de esta manera el poeta el propio héroe de su relato, traspasado al propio infierno que se ha inventado.

Por otra parte, la organización discursiva del texto poético en espacios escénicos concretos (o estancias) responde a la calidad y profundidad de los llamados pecados que recibirán su respectiva condena. Así el texto propone -en tanto ensayo que es- una teoría ética y moral que, referida al más allá que se inventa, recae o se refiere a todos los vivos, llamados por el histrión a leer e interpretar este sombrío informe que versa sobre los males de la humanidad. El histrión directamente, a través del libro, tanto denuncia como condena... ¿qué cosas?:

Las malas intenciones. Las fornicaciones. Los robos. Los homicidios. Los adulterios. La avaricia. La maldad. Los engaños. Las deshonestidades. La envidia. La difamación. El orgullo. El desatino (2006b: 103).

¿Pero hacia dónde nos conduce este infernal paseo?, ¿y qué vamos viendo a través de nuestro recorrido con el poeta Uribe? Vamos viendo muertos, una como:

Balaustrada de cráneos con cerebro puesto y dientes de hueso y muelas sonrientes, pertenecientes a los viejos muertos milenarios cuyas culpas los hicieron esqueletos descabezados que vagan indecisos hacia el infierno, llorando por la espina dorsal, o están sentados en el suelo de cascos quebrados de botellas en el purgatorio, esperando una liberación que no llega todavía.

Pertenecían a las hordas repetitivas del estilo del Gengis Khan o Tamerlán, o las de conquistas coloniales en América y Oceanía y África y Asia, de las guerras napoleónicas, de la primera guerra mundial llamada gran guerra, 
que dejaron sembradas de huesos estériles las tierras que asolaron, y las guerras civiles de los últimos siglos (como la de España por ejemplo entre 1936 y 39); y sobre todas, la espantosa y más que grande guerra mundial segunda.

Tropezábamos con huesos de brazos y piernas y con vísceras de cuerpos abandonados por esta vía (2006b: 59).

Así el infierno es el invento resultante de nuestro propio horror y crueldad, como lo señala un sujeto del texto: "En la realidad del mundo vivido hemos ido construyendo las terribles edificaciones y modelando los paisajes de decepción del Otro Mundo" (2006b: 68) ${ }^{4}$. El histrión es, de este modo, tanto el pasajero como el espectador de estas escenas del infierno y la muerte.

El inferno, lugar después de la muerte, lugar de muerte. "Lugar de aporía”, sin duda, al decir de Derrida, en tanto el pasar es un detenerse ahí precisamente en el hoyo o fosa atiborrada de cuerpos que es la visión del infierno presentada por el poeta, más allá de su propia muerte contemplada tanto en cuerpo como en psique y aún esperando el juicio final y el ansiado perdón del cielo, ahí donde de manera promiscua los cuerpos de los pasantes se detienen, "se comprimen y se hacen hoyo negro cada vez más pequeño hasta constituir un punto indivisible a simple vista (la aporía en Derrida es lo mismo), y acaso aún a través de microscopios, por potentísimos que fueren" (2006: 68). "Lugar de la aporía”, porque como nos recuerda Derrida el testimonio del pasar:

También nos pone, por así decirlo, sobre la pista del aporos o de la aporía: lo difícil o lo impracticable, aquí, el pasar imposible, rechazado, denegado o prohibido, incluso -lo cual puede ser también otra cosa muy distinta- el no-pasar (1998: 25).

Derrida, siguiendo la formulación de Heidegger, no duda en detenerse en la muerte, con el fin de traspasar "el límite de la verdad" señalado por Diderot, justamente donde se encuentra el nexo con lo propio e irreductible

${ }^{4}$ Arturo Leyte, en este mismo sentido, reflexiona sobre la función representativa de arte, en vista de los hechos terribles que han "modelado", de manera inversa a como lo propone Uribe, "los paisajes de decepción” del más acá. Señala el autor respecto del Holocausto, Vietnam y las Torres gemelas: "tal vez sean imposibles de representar en un cuadro y, que suponiendo que lo fueran, no podrían ser captados como figuras, porque en cierto modo esos caso vienen a revelar la caída de la forma de representar natural. Pero nuestra pregunta tiene que indagar acerca de la causa de esta dificultad, de esta imposibilidad" (2006: 9). 
del sujeto, su ipseidad en la muerte. La refutación de la aporía es, en cierto sentido, refutación de la identidad del pasajero, en tanto "en lo que concierne al umbral de la muerte, nos encaminamos aquí hacia una determinada posibilidad de lo imposible" (1998: 28).

Y esta aporía del pasar o de la muerte como detención del tránsito es justamente atisbada, descubierta o anticipada por el autor metaléptico que se introduce en la ficción creada, poniendo justamente su nombre en el lugar de la aporía, en ese lugar que llamamos muerte. Antes de Apocalipsis apócrifo lo va enfatizando uno de los sujetos del libro $A$ peor vida, publicado en el año 2000 por el poeta Uribe. En ese texto ya se nos está invitando a atisbar las extremas condiciones de lo mortal, pero a través de la propia mención del nombre propio y de la visión del propio cuerpo ante sus horrores carnales. Antes de eso el sujeto nos hablará directamente: "Tú que pasas de largo. / No estás más que de paso" (Uribe, 2000: 85). "Atención, tú que pasas. / Tú que pasas entiéndeme o atiéndeme. / Yo fui también uno que pasa" (2000: 117). Ser ahi es ya entonces pasado: un yo fui en el fin de mis días. Luego, un sujeto dirá desde su (no) mundo:
No soy el viudo, soy el muerto que deja viudos sus alrededores. La agonía conozco, la del huerto. Lo sé muy bien: He muerto. No me llores. Armando Uribe yaces sin dolores ya desde el día de tu concepción. A estas alturas por debajo el león del polvo es un montón de roedores (Uribe, 2000: 118).

Una cita de Bennington y Derrida viene nuevamente al caso: "Se dirá, por consiguiente, que, incluso estando yo vivo, mi nombre señala mi muerte. Es ya portador de la muerte de su portador. Es ya el nombre de un muerto, la memoria anticipada de una desaparición" (1994: 124-126; 163).

Armando Uribe Arce, nombre de un muerto, como el del propio Derrida, pero también nombre de héroe que relata sus memorias del más allá, desde un más acá desconcertante: el poema metaléptico y aporético del paso hacia el otro mundo. Héroe que se debate, otra vez, entre cielo y el infierno.

Finalmente, ¿qué es lo que se detiene en ese lugar que llamamos muerte? Se detiene tanto la figura o el sujeto de la metalepsis y de la aporía, como el propio espectro del autor en el espacio literario de su propia-muerte; o más precisamente su condición autorial anudada a su propio cuerpo de carne y 
psique. Dicho de otra manera, en ese lugar se detiene lo que entre el cuerpo y la figura hay de la propia persona. Es, en última instancia, esta noción la que se descompone en el infierno de lo propio, sea éste apócrifo o verdadero, con lo cual se evidencian las relaciones profundas entre el discurso literariopoético y el discurso antropológico-filosófico relativo a la noción de muerte. Al decir del antropólogo inglés Nigel Barley:

Las ideas relativas a lo que significa estar muerto siempre forman parte de una idea más general de lo que significa ser un ser humano vivo, y (el) comportamiento funerario y las creencias existentes en todo el mundo son interpretables como un prolongado diálogo acerca de la noción de persona (2005: 34).

¿Qué sucede con la persona que muere? Esa pregunta es también el "diálogo inconcluso" del discurso literario (Blanchot). Todo poema es un diálogo sobre la identidad y el destino de la persona que va a morir o ha muerto; discurso antropológico y filosófico desde la muerte sobre y para la vida, o entre ambas; heterodidáctica (del más allá) sobre la vida y la muerte. La relación entre figura, persona, cuerpo y muerte es la que se poetiza constantemente en Uribe, sea en forma de testamento, memoria o epitafio. La poesía es un discurso sobre la noción de persona.

Una visión más del histrión viene a ser fundamental después de este infernal recorrido: la visión de la luz que redime al histrión de su condición de cadáver penitente, de espectro condenado. Es así que el cuerpo logra la unión con el alma y acaso la utopía del paraíso sucede y se enuncia desde y en el mismo infierno: el espectro desaparece en la luz. Escribe el Histrión Uribe, en el límite de su apocalipsis y a propósito de su paso por el ámbito del terror:

Entonces, multiplicando esta experiencia, poniéndome sin vacilar en el caso de los demás, diciendo Miserere nobis, voy concluyendo que todo es perfecto y hasta feliz y que no somos los humanos tan miserables, ni en la vida anterior ni en las muertes actuales.

Laus tibi, Domine (2006b: 97).

Y luego:

Resonó la trompeta cuya boca es la bóveda cóncava del cielo y toda la luz 
de la gran esfera vacía interior de los cielos se iluminó de golpe, deslumbrando a las criaturas y a vegetales - que aun quedaban-y a minerales, sin distinción, y a todas las cosas existentes que todavía subsistían.

El Hijo del hombre Hijo de Dios apareció triunfante con pompas sobrehumanas y sobrenaturales. Desde allí ha de venir a juzgar a los vivos y a los muertos en Juicio Universal (2006b: 99).

Finalmente, el libro termina en clave metaléptica, esta vez con la "recomendación" del autor sobre la propia lectura del libro y el destino del humano lector:

Y desaparecimos entre las turbas gigantescas de quienes han de ser juzgados en definitiva luego de los primeros juicios personales de cuyos procesados, penitentes y condenados, tuvimos la visión que forma este libro de admoniciones, que con esto termina.

Ciérrenlo y no vuelvan a abrir hasta que oscurezca el sol, no dé su luz la luna y caigan los astros desde el cielo (2006b: 101).

Exordio de otro espectro, el histrión Enrique Lihn: "Estoy tratando creer que creo" (1989: 80). Es así la poesía, tiene fe en sus miradas 5 y en ellas se mantiene, acaso como la última imagen de Diario de muerte que no tiene punto final, se entiende, porque el histrión ha muerto y sólo quedan los borrados puntos suspensivos de ese espectro que habla: "Una oscura religiosa / desovilla el ovillo de la muerte con sus manos que se dirían de ángel" (Lihn, 1989: 81).

${ }^{5}$ La mirada tiene fe: "En lo más hondo y tenso de las Miradas -de amor o de odio, de miedo o de acecho, de seducción, conjuro, venganza, solidaridad o desafío... hay una mirada que llamaremos Última (y Primera). Será aquella que mira hacia más lejos, a lo remoto insondable, con profundidad (...) Es una mirada sin tiempo, que ahí está y después no está y sin razón, que finge llegarnos de otros lados pero que tampoco emerge de nuestros propios ojos y que sí se reitera en algunos seńalados momentos de la existencia... pero que siempre palpita vacía y transparente. Mirada siempre del Deseo; esquiva y carente de leyenda en palabras; pero siempre recordando un mensaje nunca develado del todo. Mirada de la Vida y Mirada de la Muerte, del aquí y el allá, del antes, ahora y después. Mirada Última, Mirada primera (...) Con la muerte, esa Mirada se va... ¿A dónde? ¿Hacia dónde apuntaba y con tanta insistencia? Entonces, sólo queda decir de una fe hecha Mirada, más allá de definiciones y credos" (Breyer, 2005:389). 


\section{REFERENCIAS}

Aldunate, Pedro. 2009. Diario de muerte de Enrique Lihn y Apocalipsis apócrifo de Armando Uribe: Escenas del Histrión y la Muerte. Tesis doctoral: Concepción, Chile: Universidad de Concepción. Tesis inédita.

Barley, Nigel. 2005. Bailando sobre la tumba. Barcelona: Editorial Anagrama S. A.

Bennington, Geoffrey y Derrida, Jacques. 1994. Jacques Derrida. Madrid: Ediciones Cátedra S. A.

Breyer, Gastón. 2005. La escena presente. Buenos Aires: Infinito.

Deleuze, Gilles y Guattari, Félix. 1990. Kafka. Por una literatura menor. México, D. F: Ediciones Era, S. A.

Derrida, Jacques. 1997. "Exordio a los Espectros de Marx". En La invención y la herencia. Espectros y Pensamiento Utópico. Cuadernos Arcis-Lom, $\mathrm{N}^{\circ}$ 2. Santiago: Universidad Arcis y LOM Ediciones.

Derrida, Jacques. 1998. Aporías. Morir-esperarse (en) "los límites de la verdad". Barcelona: Ediciones Paidós Ibérica, S. A.

Genette, Gérard. 2004. Metalepsis. De la figura a la ficción. Buenos Aires, México D. F: Fondo de Cultura Económica S. A.

Leyte, Arturo. 2006. El arte, el terror y la muerte. Madrid: Abada Editores, S. L.

Lihn, Enrique. 1989. Diario de muerte. Santiago: Editorial Universitaria. Merquior, José Guilherme. 1999. "Naturaleza de la Lírica”. En: Teorías sobre la Lirica. Comp: Fernando Cabo Aseguinolaza. Madrid: Arco/Libros, S. L.

Rimbaud, J. Arthur. 1994. Una temporada en el Infierno. Madrid: Visor Libros.

Uribe Arce, Armando. 2000. A peor vida. Santiago: Lom Ediciones. . 2006a. La fe el amor la estupidez. Santiago: Editorial Universitaria. . 2006b. Apocalipsis apócrifo. Santiago: Editorial Norma. 